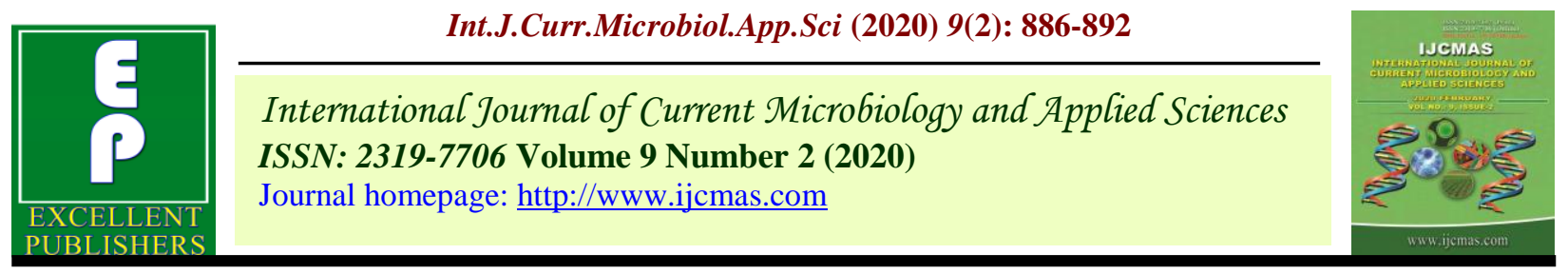

\title{
Comparative Study of the Design of Micro Irrigation Systems of Different makes for the Greenhouse Cultivation in the Southern Parts of Karnataka
}

\author{
Shrikant ${ }^{1^{*}}$ and H.G. Ashoka ${ }^{2}$ \\ ${ }^{1}$ College of Agricultural engineering, UAS, GKVK, Bengaluru - 560065, Karnataka, India \\ ${ }^{2}$ Directorate of Research, UAS, GKVK, Bengaluru - 560065, Karnataka, India
}

*Corresponding author

\begin{abstract}
A B S T R A C T
Keywords

Application

efficiency,

Horsepower,

Pipelines, Pressure

compensating

Article Info

Accepted:

08 January 2020

Available Online:

10February 2020

The study was undertaken in Southern parts of Karnataka to evaluate and to assess the design and performance of the different make drip irrigation systems in Greenhouses. Information about farmers and other details were collected from different dealers of respective company makes. The three greenhouses from each companies, which were selected for the study. The results on the design indicated that all the greenhouses having good operating system, but the six of them were not capable to operate the system results in poor performance. The hydraulic parameters such as coefficient of manufacturer variation, emission uniformity, uniformity coefficient, application efficiency and distribution efficiency were found to be excellent at both 0.75 and $1.00 \mathrm{~kg} / \mathrm{cm}^{2}$ operating pressure for all the irrigation system of different makes. However, the emitter flow variation observed to be acceptable only for company $\mathrm{A}, \mathrm{C}$ and $\mathrm{E}$ at $1.00 \mathrm{~kg} / \mathrm{cm}^{2}$ operating pressure and it was not acceptable at $0.75 \mathrm{~kg} / \mathrm{cm}^{2}$ for all the irrigation makes. The value of emitter exponent and discharge coefficient varied between 0.37 to 0.79 and 2.72 to 3.34 respectively, which indicates the flow is almost turbulent. Hence all company drippers were found to be in the range of non-pressure compensating. The company A having better hydraulic efficiency followed by company B, C, D, and E. The cost of installation per acre for all the systems was found to be in the range of Rs. 45000/- to 52000/-.
\end{abstract}

\section{Introduction}

Water shortage and absence of water resource management technologies are common challenges faced by majority of small and marginal farmers in the fast emerging countries like India. In order to solve the problem of water shortage in agriculture, it is necessary to develop water-saving management technologies. Irrigation water is provided to the plants to replace soil moisture at root-zone when natural rainfall is insufficient or poorly distributed. The efficient utilization of irrigation water is possible by the adoption of high efficient irrigation system, such as, micro-irrigation system.

Drip irrigation method is one of the best water application methods that have been used in the world among the other irrigation methods because of its good and high uniformity and 
high water use efficiency. Micro-irrigation systems in greenhouses have not been studied and compared with different make under actual field situation. Hence, it is proposed to study the design of micro irrigation systems under greenhouse condition. As the micro irrigation systems are appear to be problematic in many of the greenhouses and also farmers are experiencing poor system design and clogging with the systems, low efficiency distribution networks, insufficiency in maintenance, repair works and friction losses.

Therefore, the study has been taken to evaluate and assess the performance of the different greenhouse systems of different makes in the Southern parts Karnataka state.

\section{Materials and Methods}

The present study was carried out during 2018-19 in the greenhouses of various taluks in southern Karnataka, namely Doddaballapura, Sakaleshpur, Malur, Sidlaghatta, Chikkaballapur, Ramanagar, Bangalore north and Hoskote. The details of greenhouse growers were collected from the different irrigation companies, and they are named as A, B, C, D, and E.

Proper design is very important for the successful operation of the micro irrigation system. The design of the micro irrigation system is made by considering certain factors including agro climatic conditions, crop physiology, soil characteristics, water source and other engineering factors. Evaluation of such design is very much necessary for the different make drip irrigation installations in greenhouses about the suitability of pump, head loss, horse power, discharge and pressure.

Finally the existing Pump HP capacity in the green houses which was compared with the calculated HP for the individual greenhouse. After analysing the data, we can conclude that whether the system design is sufficient to operate the drip system or not.

The observations on length, internal diameter and discharge of sub main and drippers discharge are calculated to find the required horsepower of the system. Calculated and compared the motor size, the frictional loss in the laterals, sub mains and mains.

To estimate the friction head loss of drip irrigation laterals, the Darcy-Weishbach equation for smooth pipes in drip irrigation can be combined with the Blassius equation as follows

$\mathrm{H}_{\mathrm{fl}}=\mathrm{K} \times \mathrm{L} \times \mathrm{Q}^{1.75} \times \mathrm{D}^{-4.75} \times \mathrm{F} \longrightarrow$

Where,

$\mathrm{H}_{\mathrm{fl}}=$ Frictional loss in lateral pipes

$\mathrm{K}=\mathrm{A}$ constant whose value is $7.89 \times 105$ for SI unit of water at $20^{\circ} \mathrm{C}$

$\mathrm{L}=$ length of the pipe in, $\mathrm{m}$

$\mathrm{Q}=$ rate of flow in pipe, $1 / \mathrm{sec}$

$\mathrm{D}=$ diameter of the pipe, $\mathrm{mm}$

$\mathrm{F}=$ factor of the multiple outlet flow.

The value of $\mathrm{F}$ is 0.376 and 0.389 for laterals and sub main respectively. The value of $F$ is 1 for mainline as the main is having only few outlets for sub main connections. Christiansen's formula (1942) is used to calculate the $\mathrm{F}$ values.

The system design is divided in sequence as main, sub main and lateral and there could be one or few sub mains and each sub main has got few laterals. The drippers are positioned on the laterals to irrigate the fields.

The rate of discharge of each emitter and the total number of emitters of all the drippers on the laterals must have sufficient discharge capacity to accommodate flow from the main 
and sub main. As per theoretically worked out number of sub main and lateral, there should be enough pressure for the flow to meet the expected discharge from individual drippers. Any mismatching of number of sub mains, lateral and emitter capacity will result in poor discharge. Therefore, effective functioning of the drip irrigation system mainly depends on the designed discharge.

The equation 1 can also be used to calculate the head loss due to friction in sub main and mains. The head loss may vary from laterals due to varied length, diameter and discharge as suggested by Giuseppe et al., (2005). Generally, the discharge of both the main and sub main are same and equal to the value of the pump discharge.

The main and sub main friction head loss is denoted as $\mathrm{Hfm}$ and $\mathrm{Hfs}$ respectively. By using the digital Vernier callipers and measuring tape, the diameter and length of the laterals, sub main and main are measured in the Greenhouse.

For all the drip irrigation companies, the frictional loss due to filters bends, etc. is taken as $1.5 \mathrm{~m}$ for the complete drip irrigation system. The pressure drop due to filters is specified as 0.3 to $0.5 \mathrm{~m}$ (Hema Krishna, 2009).Then the total head requirement of the system is calculated by using DarcyWeishbach equation as

Hsys $=$ Head require for operation + friction loss + filter loss + bend losses

$$
\mathrm{H}_{\mathrm{sys}}=\mathrm{H}_{\mathrm{o}}+\mathrm{H}_{\mathrm{fl}}+\mathrm{H}_{\mathrm{fs}}+\mathrm{H}_{\mathrm{fm}}+\mathrm{H} \longrightarrow
$$

Where,

$\mathrm{H}_{\text {sys }}=$ Total head requirement of the system, $\mathrm{m}$ $\mathrm{H}_{\mathrm{o}}=$ Head required to operate the System, $\mathrm{m}$ $\mathrm{H}_{\mathrm{fl}}=$ Total head loss in the lateral, $\mathrm{m}$ $\mathrm{H}_{\mathrm{fs}}=$ Total head loss in the Sub-Main, $\mathrm{m}$ $\mathrm{H}_{\mathrm{fm}}=$ Total head loss in the Main, $\mathrm{m}$
$\mathrm{H}=$ Head loss due to Bends and Filters, $\mathrm{m}$

The friction losses in the suction pipes are taken as $6 \mathrm{~m}$ per $100 \mathrm{~m}$ pipe as proposed by Al-Ghobari (2005). Therefore, the head required for the pump is

HTotal

$=\mathrm{Hsys}+\mathrm{Hs}+\mathrm{Hfs}+\mathrm{Hd}+\mathrm{Hv}+\mathrm{Hfd} \longrightarrow$

Where, (Darcy-Weishbach equation)

Hsys $=$ Total head requirement of the system, $\mathrm{m}$

Hs = Total suction Head, $\mathrm{m}$

Hfs $=$ Friction loss in Suction Pipe, $\mathrm{m}$

$\mathrm{Hd}=$ Delivery head, $\mathrm{m}$

$\mathrm{Hv}=$ Velocity head, $\mathrm{m}$

Then, the size of the pumping unit can be calculated using the equation

$$
\mathrm{HP}=\frac{\mathrm{Q} \times \mathrm{H}}{75 \times \eta \mathrm{p} \times \eta \mathrm{m}}
$$

Where,

H.P = Horse power of the pump

$\mathrm{Q}=$ Capacity of the drip irrigation system, $1 / \mathrm{sec}$

$\mathrm{H}=$ Total head requirement of the pump, $\mathrm{m}$

$\eta_{\mathrm{p}}=$ Efficiency of the pump, fraction

$\eta_{\mathrm{m}}=$ Efficiency of the motor, fraction

The efficiency of the pump and motor is assumed as 90 per cent as all the pumps used are centrifugal monoblock directly coupled to the motor drive. The horse power required by the pump is calculated as per the above equation for all the greenhouses to check whether the installed pump sets are suitable for operating the system or not.

\section{Results and Discussion}

There were 15 greenhouses of different growers who were considered for the studies. The drip irrigation system of different greenhouses area ranged from 1.06 to 3.03 acre. There are 5 different drip irrigation companies who have installed irrigation 
system in the 15 different greenhouses. The details are presented in Table.1. Each grower of different companies' irrigation systems are designated in the form of codes like $G_{1}$ to $G_{15}$. The power requirement to operate the drip irrigation system is calculated by considering the various losses in the system.

The calculated horse power and existing horse power are compared to know the suitability of power to operate the irrigation system. The head losses in the different section of the drip irrigation system for the selected greenhouse are worked out by using the equation 1 to 4.The drip irrigation system is comprised of main line, sub line and laterals. The diameter of the main line in the design of drip irrigation system of different greenhouses is observed to be in the range of $63 \mathrm{~mm}$ to $75 \mathrm{~mm}$.

The sub main pipeline diameter is observed in the range of $40 \mathrm{~mm}$ to $63 \mathrm{~mm}$. Similarly, the laterals in all the greenhouses are with $16 \mathrm{~mm}$ diameter with an emitter capacity of $4 \mathrm{lph}$. and the drippers are spaced at $40 \mathrm{~cm}$ on laterals. The power requirement of the drip irrigation system is estimated for 15 farmer's field.

Among the different fields, there are 10 farmer's field having a water source as bore well and the remaining 5 farmers having a water source from a farm pond.

The frictional head losses were found out in main line, sub main line and laterals. In main line and sub main line, the frictional head loss depends on the length of the pipeline used in the greenhouse and the rated discharge flow through the pipeline.

The inner diameter of main line and sub main line is considered for finding out the frictional loss. The frictional head loss in the laterals is observed to be higher $(>1.5 \mathrm{~m})$ as the area of the greenhouse increases. Which is the case of $50 \mathrm{~m}$ or more length of the lateral. For $40 \mathrm{~m}$ or less lateral length, the frictional head loss is in the lower range of 0.5 to $1.5 \mathrm{~m}$.

Table.1 List of greenhousesof different growers

\begin{tabular}{|c|c|c|c|c|c|}
\hline Field No. & Name of company & Name of the farmers & Area (Ac) & Village & Taluk \\
\hline $\mathbf{G}_{1}$ & \multirow[t]{3}{*}{ A } & Anand & 2.02 & $\underline{\text { Singenahalli }}$ & Doddaballapura \\
\hline $\mathbf{G}_{\mathbf{2}}$ & & Sonnappa & 1.50 & Arekere & Sakaleshpur \\
\hline $\mathbf{G}_{\mathbf{3}}$ & & Ashok kumar & 2.01 & Yeswanthapura & Malur \\
\hline $\mathbf{G}_{4}$ & \multirow[t]{3}{*}{ B } & S. P Devaraj & 1.60 & Shettahalli & Sidlaghatta \\
\hline $\mathbf{G}_{\mathbf{5}}$ & & Ravikumar & 2.05 & Hunegallu & chikkaballapur \\
\hline $\mathbf{G}_{6}$ & & Murthy & 1.80 & Bhimenahalli & Ramanagar \\
\hline $\mathbf{G}_{7}$ & \multirow[t]{3}{*}{$\mathrm{C}$} & Rakesh & 2.02 & Hunegallu & chikkaballapur \\
\hline $\mathbf{G}_{8}$ & & Panduranga & 1.75 & Rajanukunte & Bangalore north \\
\hline $\mathbf{G}_{9}$ & & Nagappa & 1.60 & Arekere & Sakaleshpur \\
\hline $\mathbf{G}_{10}$ & \multirow[t]{3}{*}{$\mathrm{D}$} & Devaraj & 1.06 & $\underline{\text { Singenahalli }}$ & Doddaballapura \\
\hline $\mathbf{G}_{11}$ & & Ramanji & 1.54 & Abbanakuppe & Rananagar \\
\hline $\mathbf{G}_{12}$ & & Radhakrishna & 1.62 & Yeswanthapura & Malur \\
\hline $\mathbf{G}_{13}$ & \multirow[t]{3}{*}{$\mathrm{E}$} & Aswathappa & 2.03 & Shettahalli & Sidlaghatta \\
\hline $\mathbf{G}_{14}$ & & chandru & 3.03 & Devanagundi & Hoskote \\
\hline $\mathbf{G}_{15}$ & & Hariprasad & 1.35 & Dyvarahalli & Sidlaghatta \\
\hline
\end{tabular}


Table.2 Power requirement of the different drip irrigation systems

\begin{tabular}{|c|c|c|c|c|c|c|c|c|c|c|}
\hline \multirow{2}{*}{$\begin{array}{l}\text { Sl. } \\
\text { No }\end{array}$} & \multirow{2}{*}{$\begin{array}{c}\text { Greenhouse } \\
\text { No. }\end{array}$} & \multirow[t]{2}{*}{ Area(acre) } & \multirow{2}{*}{$\begin{array}{c}\text { Existing } \\
\text { HP }\end{array}$} & \multicolumn{6}{|c|}{ Frictional head (m) } & \multirow[t]{2}{*}{ CalculatedHP } \\
\hline & & & & Hfm & Hfs & Hfl & Hsys & Hsuc & Htotal & \\
\hline 1. & $\mathrm{G}_{1}$ & 2.02 & 20 & 8.14 & 0.58 & 10.57 & 31.30 & 2.44 & 289.99 & 19.09 \\
\hline 2. & $\mathrm{G}_{2}$ & 1.50 & 5 & 1.43 & 0.19 & 11.90 & 25.53 & 147.61 & 186.66 & 4.91 \\
\hline 3. & $\mathrm{G}_{3}$ & 2.01 & 20 & 3.27 & 0.62 & 9.69 & 25.60 & 196.33 & 235.5 & 21.48 \\
\hline 4. & $\mathrm{G}_{4}$ & 1.60 & 7.5 & 0.61 & 0.15 & 7.94 & 12.76 & 76.2 & 93.56 & 6.93 \\
\hline 5. & $\mathrm{G}_{5}$ & 2.05 & 25 & 1.45 & 2.61 & 16.68 & 32.75 & 302.58 & 356.07 & 24.03 \\
\hline 6 & $\mathrm{G}_{6}$ & 1.80 & 10 & 1.80 & 1.56 & 9.84 & 25.21 & 84.37 & 122.78 & 8.08 \\
\hline 7 & $\mathrm{G}_{7}$ & 2.02 & 20 & 1.36 & 0.30 & 11.67 & 25.34 & 310 & 348.67 & 24.53 \\
\hline 8 & $\mathrm{G}_{8}$ & 1.75 & 10 & 1.83 & 1.56 & 9.84 & 25.21 & 92 & 122.78 & 9.70 \\
\hline 9 & $\mathrm{G}_{9}$ & 1.60 & 7.5 & 2.17 & 0.34 & 2.44 & 16.96 & 77 & 98.60 & 7.30 \\
\hline 10 & $\mathrm{G}_{10}$ & 1.65 & 7.5 & 1.43 & 0.19 & 11.90 & 25.33 & 152 & 186.67 & 6.53 \\
\hline 11 & $\mathrm{G}_{11}$ & 1.54 & 5 & 1.80 & 0.21 & 13.02 & 26.33 & 158.47 & 198.23 & 8.93 \\
\hline 12 & $\mathrm{G}_{12}$ & 1.62 & 5 & 1.43 & 0.19 & 11.90 & 25.33 & 152 & 186.67 & 5.53 \\
\hline 13 & $\mathrm{G}_{13}$ & 2.03 & 20 & 3.82 & 0.28 & 5.74 & 21.84 & 275 & 313.37 & 21.14 \\
\hline 14 & $\mathrm{G}_{14}$ & 3.03 & 25 & 1.62 & 0.33 & 7.74 & 21.70 & 184.32 & 215.71 & 24.55 \\
\hline 15 & $\mathbf{G}_{15}$ & 1.35 & 12 & 1.99 & 0.15 & 7.45 & 21.59 & 168.52 & 199.70 & 13.01 \\
\hline
\end{tabular}

The Table. 2 reveals about the different head losses in the mainline, sub mainline and lateral line. The other losses include the total suction head loss and system head loss in the drip irrigation system.

Sum of all the above losses, the total head loss to operate the system was calculated. Here, the system operating pressure considered as $1.00 \mathrm{~kg} / \mathrm{cm}^{2}$ and pressure drop in the filters and the pressure drop due to the bends and fittings are nearly equal in all the greenhouses with slight variation according to the area of the greenhouse.
Finally, the capacity of the operating system to operate the drip irrigation system was worked out using the equation 4 . The results indicated that as the area of the greenhouse increases, the total head required to operate the drip irrigation system also increases.

The results of the power requirement of the drip irrigation system presented in the Table.2, shows that among the total of 15 greenhouses, 9 greenhouses $\left(\mathrm{G}_{1}, \mathrm{G}_{2}, \mathrm{G}_{4}, \mathrm{G}_{5}\right.$, $\mathrm{G}_{6}, \mathrm{G}_{8}, \mathrm{G}_{9}, \mathrm{G}_{10}$ and $\mathrm{G}_{14}$ ) having the sufficient pump size to operate the drip irrigation system. 
The calculated pump size (HP) is less than the existing pump size (HP) and this proves that the design of the drip irrigation system is adequate to operate the drip irrigation system. Observation of the 4 Greenhouses $\left(\mathrm{G}_{3}, \mathrm{G}_{12}\right.$, $\mathrm{G}_{13}$ and $\mathrm{G}_{15}$ ), revealed that the calculated pump size is slightly more than existing pump size.

However, with some modification in the greenhouse, the system can be operated efficiently. The observation of the 2 Greenhouses $\left(G_{7}\right.$ and $\left.G_{11}\right)$, indicated that the calculated pump size is higher than the existing pump size. Therefore the pump is not sufficient to operate the drip irrigation system effectively.

Poorly designed system results in the overall poor performance with low-pressure head, large variation in operating pressure between the lateral in let and end plug position of the lateral. Therefore the design is inadequate to operate the drip irrigation system. The design evaluation of the drip irrigation system of different greenhouses shows that 60 per cent farmer's greenhouses were have good operating system and 26.66 per cent of them need some modifications in the field.

Remaining 13.34per cent systems of green houses were not capable to operate the system. Also, in some of the fields, lower pump size was observed which results in poor performance of the system.

\section{References}

AL - Ghobari, (2005) Trickle Irrigation Application Uniformity from simple Emitters, Trans. Amer. Soc. Agric. Eng., 16(6):1108-1111.

Bilal, A., Fatih, C., Yavuz, and Ramazan, T., 2011, Research on Drip Irrigation System Performance under Greenhouse
Conditions, Bulletin UASVM

Agriculture, 68(1): 1843-5246.

Bezdek, J.C. and Solomon, K., 1978, Approximating friction factors for trickle tubing. $J$. of irrigation and drainage engineering division ASAE, 104: 351-359.

Christiansen, J, E., 1942. Hydraulics of sprinkling systems for irrigation. Trans. Amer. Soc. Agric. Eng., 107: 221-239.

Gerrish, P. J., Bralts, V. F. and Shayya, W. H., 1996, An improved analysis of micro irrigation hydraulics using a virtual emitter system. Transactions of the American Society of Agricultural Engineers. 39(4):1403-1410.

Giuseppe. P., Domenico, P. and Pietro, D., 2005, Simplified procedure to evaluate head losses in drip irrigation laterals. Journal of Irrigation and Drainage Engineering, 131: 525-532.

Hema Krishna, 2009. Study of hydraulic parameters of drip irrigation systems in farmers' fields under different crops. M.tech Thesis (Unpub), Acharya N. G. Ranga Agricultural University.

Krishna Reddy, Y. V., Sirisha Adamala. and Bachina Harish Babu, 2017, Case Study on Performance Evaluation of Drip Irrigation Systems in Selected Villages of Guntur District, Andhra Pradesh, India. Int. J. Curr. Microbiol. App. Sci, 6(2): 437-445.

Shete, D. T.,2005. Determining of factors for laterals in micro-irrigation. In: Chaudhary M.L., Chandra P. and Mishra P. (Eds.) Proceeding of International conference on Plasticulture and Precision Farming, held during November 17-21, 2005 at New Delhi. p. 91-97.

Yeldirim, G., and Agiralioglu, N., 2004, Linear solution for hydraulic analysis of tapered micro irrigation laterals. J. Irrig. Drain. Eng., 130(1): 78. 


\section{How to cite this article:}

Shrikant and Ashoka. H.G. 2020. Comparative Study of the Design of Micro Irrigation Systems of Different makes for the Greenhouse Cultivation in the Southern Parts of Karnataka.. Int.J.Curr.Microbiol.App.Sci. 9(02): 886-892. doi: https://doi.org/10.20546/ijcmas.2020.902.106 